striking as these figures undoubtedly are, they by no means represent the whole result.

Everyone who suffers from syphilis in its infectious stages becomes a potential focus of infection and a source of danger to others. Conversely, every case of syphilis prevented becomes a potential source of prevention and a safeguard to others. Thus circumcision may not only confer a benefit upon the circamcised but also on others with whom he may come in contact. Unfortunately, it is quite impossible to bring any direct numerical evidence to bear upon this point, but a hypothetical case, based on a very moderate computation, will serve to show how in a very short space of time one focus of infection may grow into several hundred. Take, for example, a man with a syphilitic chancre on the prepuce; in all probability he will sooner or later infect some woman, who, if he be single, is likely to be of the prostitute class. Supposing this to occur, the woman, in all human probability, will in due course infect several other men, who, in their turn, will infect as many women, each of whom again is likely to infect several more men, and so on, the disease being spread and the numbers increasing with alarming rapidity. When one considers that the primary source of infection might have been prevented by circumcision, and that the whole series of cases which have been assumed to follow in its wake each in their turn become fresh sources of infection, capable under favourable circumstances of producing like results, it becomes impossible to estimate the number of cases which might be prevented by circumcision, if universally practised. All that can be said is that if the immediate effects are great the remote effects must be far greater.

But, again, the matter does not end here. In syphtlis it is not only the guilty who suffer, but the innocent suffer with the guilty and the sins of the fathers are in very trath visited upon the children. Deplorable as such a state of affairs may be, it is nevertheless far from uncommon for a married man to infect his innocent wife, and through her his offspring which is yet unborn. Is there any direct evidence to show that the practice which I am adrocating will materially diminish this massacre of the innocents? Fortunately there is. Jonathan Hutchinson ${ }^{12}$ found that out of 97 female hospital patients who came under his observation in one year for venereal disease 92 were Christians and five were Jews. Of the former 61 were married, and at least two-thirds of these had apparently contracted syphilis from their husbands. Again, the same observer ${ }^{13}$ found, out of 252 children under five years of age who came under his care in the course of a year, 179 Christians, giving 27 cases of congenital syphilis, and 73 Jews, giving only three cases of congenital syphilis. These statistics clearly show an enormous reduction in the case-incidence of syphilis among the women and children of the circumcised Jews, and in view of what has already been said the only deduction which can reasonably be drawn from their study is that if the practice of circumcision were to become as general among Christians as it is among their Jewish brethren a proportionately great reduction of the case-incidence of syphilis would take place among their women and children. In other words, a not inconsiderable number of innocent women and children would be spared the indignity of being doomed to suffer, through no fault of their own, from a loathsome and lifelong disease-a no mean result, whether considered from a sentimental or practical point of view, and one which, in the absence of any other reason, should amply prove that " the end justifies the means."

Before concluding, however, I should like to say a few words about the operation itself. Simple as the operation is, certain details must be observed in its performance if the result is to be successful for the special purpose which one has in view. It must ever be borne in mind that the special object to be attained by circumcision as a preventive of syphilis is not only the removal of the prepnce, but, as far as possible, the obliteration of all folds about the glans. The advice usually given to the novice is to be careful not to remove too much skin. Consequently too little, rather than too much, is often removed. The result is that the retropreputial fold still persists, a matter of some moment from the present point of riew. The incision should be made in such a way as to be oblique from above downwards and forwards, and slightly concave forwards so that when the skin retracts it may sit snugly behind the corona. In other words,

12 Medical Times and Gazette, Dec. 1st, 1855. 13 Ibid. the plane of the incision should be as nearly as possible parallel to the plane of the corona. The reflected layer of the prepuce-the so-called mucous layer-which has been left untouched by the first incision, should, after being slit up and reverted, be carefully trimmed around the corona glandis in such a way as to allow the cut edge to come neatly into contact with the cut edge of the part first removed. A wedge-shaped piece of the frænum should always be removed. By so doing the folds which exist on either side are obliterated and the cedematous nodule which is liable to form at this point is prevented. All rough and unnecessary manipulation is to be avoided, as, the cellular tissue being very loose, cedema is easily produced, which not only retards healing but becomes a source of anxiety to the child's friends. Whether my premisses are correct and my deductions sound I must leave others to judge. If they be so, then it becomes the imperative duty of everyone who is cognisant of the facts to exert his influence for the benefit of humanity at large by securing, as far as possible, the efficient circumcision of every male child who comes under his notice. For my own part I am convinced that any community among which syphilis is rife and which imposes upon itself the obligation to circumcise every male child who appears in its midst will confer a great and lasting benefit upon its members, both present and yet to be, at an infinitesimal outlay.

Beaumont-street, W.

\section{ON A NEW METHOD IN THE DISCISSION OF SOFT CATARACTS.}

BY PERCY DUNN, F.R.C.S. ENG., OPHTHALMIC SURGEON TO THE WEST LONDON HOSPITAL.

THE present-day method of treating soft cataracts by discission is to use a very fine cataract needle, to make $a$ small incision in the capsule of the lens, to employ care not to break up the lens substance too freely, particularly to avoid allowing any of the aqueous to escape during the procedure, and, in short, to aim at securing a gradual absorption of the soft lens matter from the anterior chamber. The effect of this gradual absorption is that some months generally have to elapse before the process is completed. Occasionally, moreover, it happens that the operation has to be repeated owing to the process of absorption having been arrested by the cicatrisation of the capsular wound. Thus further time is lost before the whole lens matter is absorbed and the object of the operation is attained. The disadvan. tage of this loss of time is obvious, but the procedure has another drawback. There is the possible risk of the swelling of the lens, caused by the imbibition of the aqueous, giving rise to increased intra-ocular tension, necessitating further and immediate interference.

Reflecting, therefore, as I have done for some time, upon these facts, it seemed to me that the operation of discission as practised in the present day by no means fulfilled the requirements of the surgeon and that it was capable of improvement. As a matter of fact, the point upon which the present method of discission wholly binges is that of the fear of causing glaucomatous symptoms by a too free disturbance of the lens substance. It is clearly for this reason that only a limited incision is made in the capsule and care is exercised to secure that only a small quantity of soft lens matter shall escape into the anterior chamber at a time.

The first consideration, then, which seemed to demand attention was how to deal with this risk of the occurrence of increased tension. The solution of the problem quickly presented itself. All that was necessary in order to meet the difficulty appeared to be to allow the aqueous to drain away from the anterior chamber before withdrawing the needle. The conclusion is plain that with the aqueous removed any further rapid swelling of the lens wonld be impossible, and with the globe in a condition of minus tension owing to the loss of the aqueous the subsequent restoration of the anterior chamber would necessarily depend upon the degree of swelling of the lens which was present and upon the amount of soft lens matter which was free and ready for absorption. To put the same matter differently, it is reasonable to conclude that the condition of the lens after the needling would determine the degree of the restored tension. 
With a swollen lens the aqueous would probably only be resecreted to the amount which was needful to restore the tension to the normal, and thus it might come to pass that part of the latter might be due to the swollen condition of the lens and the presence in the eye of broken.down soft lens matter, and part to re-secreted aqueous. For this reason, therefore, it is not possible to conceive that glaucomatous symptoms could arise under these circumstances-that is to say, after the aqueous had been allowed to escape at the time of the operation. This assumption is based upon the fact that the intra-ocular tension of a healthy eye is regulated by its requirements; in other words, the lower the tension the greater is the secretion of aqueous, the higher the tension the less the secretion. Thus, assuming these premisses to be correct, three advantages could be claimed for this new method of procedure : (1) the avoidance of the risk of causing increased tension; (2) the possibility of freely breaking up the lens; and (3) the rapid absorption of the soft lens matter.

But, again, a lowered tension must imply a more rapid circulation of fluid through the eye, and it is precisely that condition of affairs which is most to be desired in cases of discission, for the more rapid the circulation of the intraocular fluid the more rapid must be the absorption of the soft lens matter. Quite possibly the slowness of the absorption following the present-day method of discission is partly, if not greatly, due to the persistence of a slightly raised tension which causes the circulation of the intra-ocular fluid to be a leisurely process.

It was not long before the opportunity occurred to me of putting these conclusions to the test. The case was that of a child whose right lens I had needled some months previously for congenital cataract. Only one needling was necessary, but at least three months elapsed before the pupil was black. The operation upon the left lens was considerably delayed owing to the supervention of an attack of scarlet fever. When, however, the child had made a good recovery from this, I proceeded to operate upon the second eye as follows :-

Chloroform having been administered I took a broad, instead of a fine, cataract needle, and the pupil being well ander atropine, I passed the former into the anterior chamber and the lens, making a vertical and horizontal incision in the capsule. I then freely broke up the lens and afterwards withdrew the needle until the point only remained in the anterior chamber. Next, I partly turned the needle on its axis, by which I allowed all the aqueous to escape slowly from the eye. The globe and conjunctival sac were thoroughly douched with chinosol ( 1 in 4000); some drops of atropine of the strength of two grains to the ounce of water were instilled, and a pad of chinosol gauze and a bandage were applied. The result of the operation was as follows. There was no reaction; in four days' time the pupil was quite black, and all that was left of the lens was a small quantity of soft lens matter lying at the bottom of the anterior chamber. After the lapse of 14 days there was merely a trace of this lental remnant to be seen.

The above facts speak for themselves. They show, I think, that the rapid absorption of soft lens matter from the anterior chamber is only possible when the intra-ocular ension has been reduced by the removal of the aqueous.

A word may now be said regarding the possibility of any untoward effects following the evacuation of the aqueous under these circumstances. The first and only complication which suggests itself is that of iritis, and it might be supposed that in the event of its supervention its origin would be due to mechanical irritation caused by the presence of the broken-up lens matter. But the doctrine that mechanical irritation per se can excite inflammation anywhere in the tissues is not one which, in the present day, receives support from scientific testimony. I cannot, therefore, conceive how iritis could occur in these cases unless there was a failure to secure strict antisepticism at the time of the operation.

Some confirmation of the expediency of allowing the aqueous to escape in the discission of soft cataracts occurs in many cases of extraction operations for senile cataract. In these cases no difficulty is experienced in obtaining the fairly rapid absorption of the lental débris which it has been found impossible to remove after the extraction of the lensa result which, I believe, must be chiefly due to the lowered tension in the eye caused by the necessary steps of the operation.

Wimpole-street, $\mathbf{w}$.

\section{A CASE OF HYDATIDS PRIMARILY AFFECTING THE LUNG.}

BY JULIUS CAESAR, F.R.C.S. IREL., L.R.C.P., L.R.O.S. EDIN,

That hydatids primarily affecting the lung are exceedingly rare is evidenced by the very brief reference made to them in those works which discuss the matter, some writers stating that they are hardly ever met with and others ignoring the subject altogether. Mr. Norman Porritt in his work on "Intra-Thoracic Effusion" gives but one case.

That the following case was one of hydatids originating in the lung will, I think, be beyond dispute after a consideration of the following facts. 1. The liver was of normal size. 2. The hydatids could not bave originated in the pleura, as had they done so, according to Dr. Clifford Allbutt, the costal and pulmonary pleuræ would have become fused, but I was able to sweep my hand round the inter-pleural space. 3. There was no discoverable communication between the abdominal and pleural cavities. 4. I found the growth springing from, or attached to, the base of the lung. There was nothing in the history of the patient to suggest the source of the infection beyond the fact that some six years ago she was laid up for about nine months with what her medical attendant stated to be blood-poisoning from drinking foul water. She never lived where dogs were kept (i.e., kennels) or out of England. She was said to have complained for some years of a pain in her right side, but this was not severe enough to induce her to seek advice for it.

The patient first came under my care in July, 1900, complaining of vomiting, diarrhœa, and severe pains shooting across her abdomen. By the end of a week these had completely subsided and she resumed her domestic duties and continued to perform them up to August 10th, when she was suddenly seized with a recurrence of these symptoms and in addition she complained of shortness of breath and of expectoration of a clear viscid fluid. Her respirations were 36 , her pulse was 94 , and her temperature was $98^{\circ} \mathrm{F}$. Auscultation revealed nothing to account for the dyspncea and percussion only doubtful dulness at the base of the right lung. Vocal fremitus and vocal resonance were normal. On the 11th the patient was in much the same state except that the bowels were more relaxed; the expectoration was, if anything, more viscid and was accompanied on two occasions by a distinct streak of blood which showed no inclination to spread. On the 12 th she had a very bad attack of dyspncea which lasted for a few hours and then subsided. The pain was decidedly more localised to the right side. The vomiting had ceased and the bowels were less relaxed. On the 13th her breathing was much easier but the expectoration continued and looked like the partially coagulated white of an egg. The dulness was more definable. The respirations were 30 , the pulse was 80 , and the temperature was $98^{\circ}$. On the 14th she was much the same; the bowels acted normally. For the next three days her state did not materially change except that she had to be propped up in bed to assist her breathing and the dulness bad become more marked and the dyspnœea more frequent. She had no bad attack of dyspnoa on the 18th, but she could not lie down because of the cough and the expectoration. The latter had become very viscid and was always accompanied by the streak of blood. The dulness reached to within two fingers' breadth of the inferior angle of the scapula, below which point vocal fremitus and vocal resonance were abolished. The respirations were 40 , the pulse was 86 , and the temperature was $98^{\circ}$. She had a very bad day and night on the 19 th, the dyspnoea, congh, and expectoration being incessant and quite prostrating her after each attack. The temperature rose to $99^{\circ}$, which was the highest point it had as yet attained. The symptoms having undergone no improvement since the 19th, on the 20th I tapped the thorax at the ninth interspace a little behind the axillary line, and withdrew about two and a half ounces of pale sherry-coloured gelatinous substance which the microscope showed to be brokendown hydatid cysts without hooklets. During the operation the patient's breathing became much embarrassed and she nearly fainted. On the 21st the tapping did not appear to have afforded her relief. Her temperature rose to $100^{\circ}$ and fine râles were heard in front just below the right nipple.

As the surroundings of the patient were not conducive to her 